\title{
Emotions and Places. An Investigation through Virtual Reality
}

\author{
Barbara Piga \\ Gabriele Stancato \\ Nicola Rainisio \\ Marco Boffi \\ Giulio Faccenda
}

Abstract

The contribution proposes the results of a pilot application of the method (exp-EIA@ 2020 and 202 I) developed within the European projects H2O20 EIT Digital (Digital Cities): AR4CUP: Augmented Reality for Collaborative Urban Planning (2019 and 2020). During these projects, we implemented an APP that favors participatory processes with citizens thanks to Virtual and Augmented Reality solutions to visualize and react to urban contexts in the current or designed condition. The method integrates experiential simulation with psychological constructs to represent the geography of experience in places. The case study presented in the paper was carried out at the neighborhood scale and investigates a particular target of users: university students in the Citta Studi district in Milan, where Politecnico di Milano and the Università degli Studi di Milano are located. The results show, on average, a positive emotional experience, primarily linked to the symbolic places of the universities. The results provide an initial basis for a collective discussion on the relationship between people and the neighborhood.This study's outcomes contributed to developing the European projects and their final product, an innovative co-design app distributed as CitySense.

Keywords

Virtual Reality, emotions, experiential simulation, co-design, app.
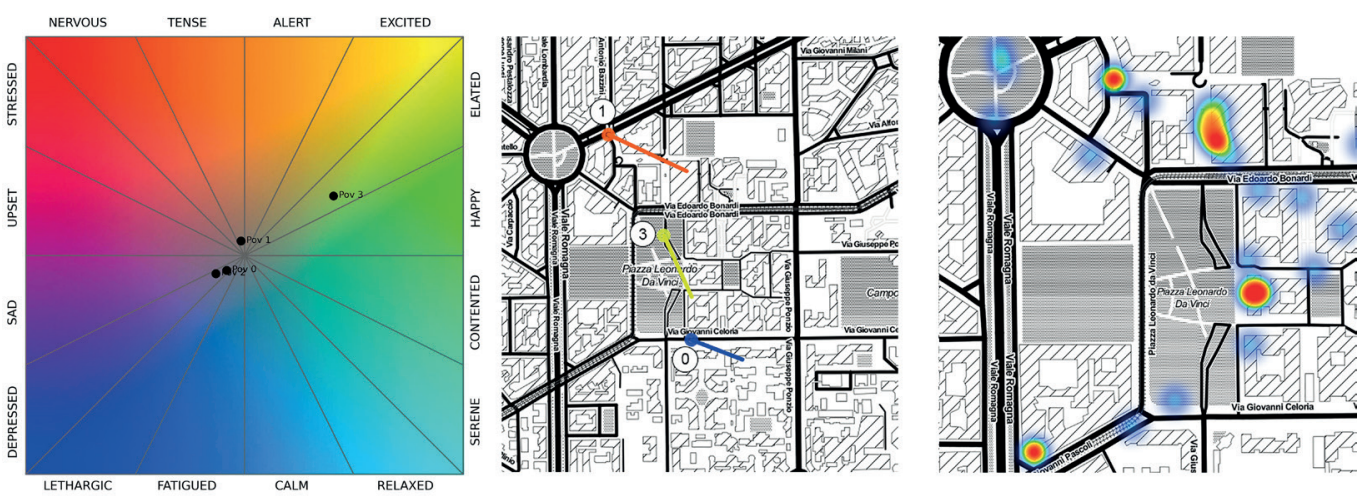


\section{Introduction}

The following study is part of two European Projects H2020 EIT Digital Project: Augmented Reality for Collaborative Urban Planning (AR4CUP) (2019 and 2020), in which an Augmented Reality (AR) and Virtual (VR) solutions where coupled with an innovative methodology for assessing people experience in place, i.e. The experiential Environmental Impact Assessment - exp-EIA ${ }^{\odot}$, i.e. two international Copyrights (BOIP N. 123453 - 06.05 .2020 and Copyright BOIP N. I 305 I 6 - 25.02.202 I - B. Piga, M. Boffi, N. Rainisio); the outcome is the AR4CUP APP (later APP), commercially named CitySense [I], based on stakeholders needs in the field of urban design [Piga et al. 20 I 9; Piga et al. 202 I].The APP enables: I) the geo-localized $3 \mathrm{D}$ visualization of urban transformation projects through mobile devices in AR or VR; 2 ) the collection and analysis of people's feedback related to the current or designed conditions. The APP end-users can be defined according to the customer's needs and, therefore, they can be residents, workers, tourists, or other stakeholders. This interdisciplinary project is jointly developed by Artefacto (technical development of the app), by POLIMI - DAStU labsimurb [2] in collaboraion with UNIMI - BAC [3] (methodology applied in the app for the collection, analysis, and representation of data), and by VTT (AR tracking and positioning). The methodology is mainly based on Architecture, Social and Environmental Psychology, and Information Technology. The first AR4CUP European Project, focused on the pre-evaluation of urban transformations, started in January 2019 and ended in December 2019 with the pilot application to the case study of the VITAE project by Covivio, Carlo Ratti Associati \& Partners. The second AR4CUP European Project, focused on the assessment of the current condition of the urban context, took place from January 2020 to December 2020 with the application both to the Città Studi district and the project The Sign by Covivio and Progetto CMR (Massimo Roj Architects). The applied methodology integrates the topics of architecture (focus on the environment) with those of psychology (focus on the experience of the subject) through the use of experiential simulations and the collection of data related to the environmental experience [Piga 20 I7]. The paper presents the testing procedure of the methodology developed for the AR4CUP 2020 project on the Città Studi district, the location of the Politecnico di Milano (Leonardo) and Università degli Studi di Milano (Città Studi). On this occasion, the APP methodology was used to evaluate the existing context.

\section{Literature Review}

The development of digital technologies and their large-scale diffusion have given a new stimulus to co-design processes and offered new opportunities for dialogue among the actors involved in urban transformations [Sanders 2002; Piga et al. 202 I]. These new forms of smart public participation are an evolution of a consolidated framework. For instance, the use of GIS views is now widespread [Al-Kodmany 1999, 2002; Peng, 200 I; Desouza, Bhagwatwar 20 I4; Hudson-Smith et al. 2005], also integrated with data sourcing through users' personal devices that provide environmental data [Evans-Cowley, Hollander 20 I ; Kanhere 2013 ; Stratigea et al. 20 15]. Besides, there is the increasing use of three-dimensional models and experiential simulations [Bosselmann, 1998, 20 I2; Al-Kodmany 2002; Piga, Morello 20 I5], in some cases associated with immersive viewing modalities. The use of experiential simulation systems, which guarantee a better understanding of the elements represented for the non-expert public, is a key element to involve citizens in a constructive dialogue [Piga 20 I8], especially if we consider the potential adverse responses to the changes and the consequent costs for businesses and the community [Münster et al. 20 17]. This approach can be potentially integrated with psycho-social analyses, which is an advantage scarcely exploited so far [Brauer et al. 2016], in order to understand and predict the perceptual and emotional response of users to the urban environment and its future developments before construction [Lundgren et al. 20 I5; Boffi, Rainisio 20 I 7]. This integration constitutes the theoretical-methodological basis of this contribution, which focuses on two main aspects. Firstly, the analysis and representation of the users' emotional urban experience, analyzed through 
psychological constructs, in cartographic form. Secondly, the evaluation of the fruitfulness of this approach in activating virtuous co-design processes. According to this perspective, this narrative of the urban space includes the lived and subjective experience of inhabitants; it does not refer to physical space only but to the place understood in its atmospheric meaning (ambiance) [Piga, Morello 20 I 5; Piga et al. 20 I6], i.e. the relationship between people and the environment. Therefore, the object of the narrative is the relationship that is established between people and the environment in space and time.

Fig. I. The four predetermined points of view.

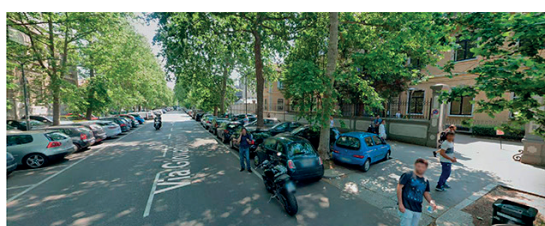

POV 0

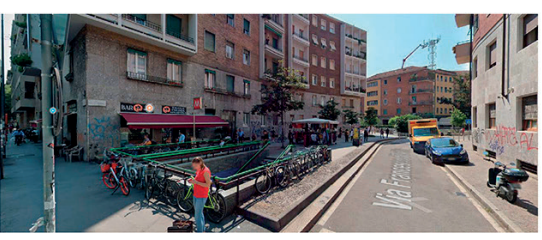

POV 1
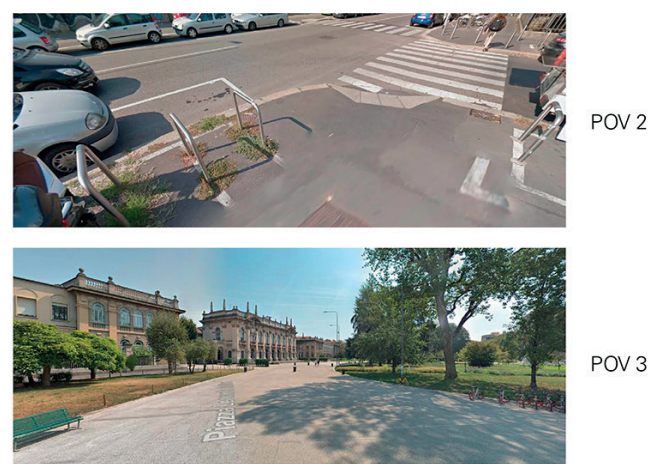

\section{Method}

The case study application allowed to evaluate citizens' experience in the Città Studi district, where the historic buildings of POLIMI and UNIMI are, in its current state. The district also hosts two hospitals, the National Cancer Foundation IRCCS and the Carlo Besta Neurological Institute. The area is mainly populated and daily frequented by researchers, professors, and students of these institutions and the residents of the neighborhood. In normal conditions, over 20,000 students reach the Politecnico (Leonardo campus) only. POLIMI international students, which number increased significantly in their past ten/fifteen years, joint the event (38 people); they represents a particularly relevant point of view, the one of international young people (generally between 19 and 25) that study at the universities of the district. The APP asks users a questionnaire that allows them to evaluate the experience lived in a place. Established psychological constructs, such as emotions, are used to collect feedback and describe people's experience [Russell, Pratt 1980].

The pilot event, called Experiencing Città Studi, was held inside one of the main buildings of the Politecnico in Città Studi, on 2 October 2020, in the form of a full-day workshop with 38 participants. Due to the general situation caused by Covid- 19 and the consequent restrictions introduced in Italy and the rest of Europe in that period, the activity took place in the form of blended workshops, i.e., with some participants in presence and others connected remotely. The event was structured in three main phases. During the first one, the POLIMI team introduced the AR4CUP European Project and the application in its primary functions. The pilot's purpose was shared, and participants were provided with guidelines that presented the instructions for the exploration and evaluation of the neighborhood through VR to be conducted during the workshop day. In the second phase of the event, the participants, after entering their socio-demographic data, filled out a first questionnaire aimed at investigating the neighborhood as a whole, then answered some questions related to four pre-determined points of view (PoV) in the area object of study and other free PoVs selected directly by the participants. The four pre-determined PoVs, considered significant for the narrative of the neighborhood, were selected by the research group (fig. I). Pre-determined PoVs were stationary even if it was possible to look around (spherical pannable panoramas). At the end of the event, the analyzed results were presented to to participants to inform a collective discussion on the characteristics of the neighborhood. 
Fig. 2. Emotional appraisal for PoVs and Città Studi (upper), emotional Città studi (lower).
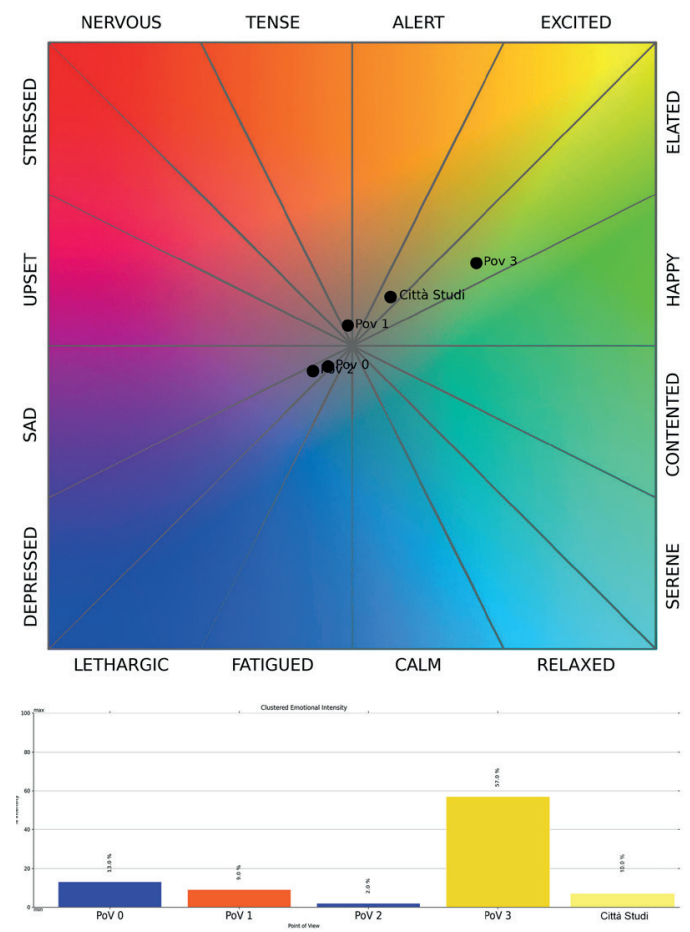

\section{Analyses and results}

For each PoV the collected answers were clustered, with the DBSCAN method [Birant, Kut 2007; Stancato, Piga 2020] and Scikit-learn 0.22 and Python 3.8 libraries, based on the position and visual target of the participants. The clusters made it possible to identify the average orientation in space for each PoV; the average emotional reaction that emerged from the analyses was then associated to each specific perspective (Copyright exp-EIA ${ }^{\odot}$ ). This process made it possible to spatialize the observers' emotions in a georeferenced way, building maps that show the emotional geography of the places. In this way, the cartographic representation constitutes a form of narration from which the relationship between the architectural space and the generated experience is deduced. In addition to the spatialized results, there are also graphs and tabular information that return the results of the analyses in numerical form. The present analysis illustrates the results related to the district as a whole and the four pre-determined PoVs in particular. From the analyses of the relationship with the Città Studi district as a whole, it emerges that the target involved has an average level of familiarity with the area (53\%). Consistently with the functions present in the neighborhood and the main activities related to the attendance of the place, the three main reasons for frequenting the neighborhood are studying (23.4\%), food services (16.8\%), and social relations (14.8\%). The relationship with the neighborhood as a whole is characterized by a medium positive and activating emotional state (corresponding to the "excited" position on the Russell quadrant) although with a low intensity (I0\%) (fig. 2). From the analysis of the PoVs, it emerges that the four views considered differ greatly from each other. PoVs 0 and 2 correspond to weakly (13\% and 2\%) negative and deactivating ('depressed') emotional states. PoV I is weakly (9\%) negative and activating ('tense'). PoV 3 is significantly (57\%) positive and activating ('elated'). If we consider the physical space characteristics, these reactions are consistent with their architectural interpretation, even if this discipline does not traditionally provide tools for directly quantifying emotional reactions. Indeed, PoV 0 and 2 are environments that lack a specific and characterizing identity, although the morphology could potentially favor positive experiential outcomes. PoV I is a highly chaotic place due to the underground stop, which is always very busy; the space is undersized compared to the number of people who gravitate there every day. PoV 3, recently redesigned, is a pedestrian-only space with green amenities and is often frequented 
Fig. 3. Key-map of the pre-determined PoVs, colored in accordance with the associated emotions.

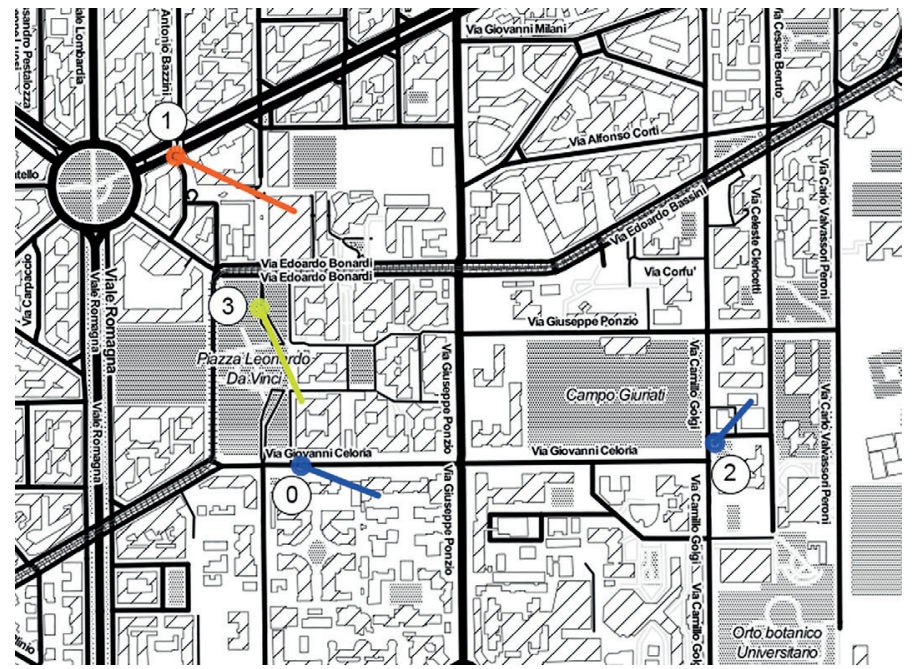

by a large number of students; moreover, the observation is attracted by the historic facade of the central building (Rectorate) of the Politecnico di Milano, which is also endowed with a sound symbolic value. In the key-map in figure 3 , it is possible to observe the PoVs and the related average direction of the gaze; each point of view and vector acquires the color corresponding to the emotion identified on Russell's quadrant. Finally, it is interesting to highlight how the average emotion associated with the neighborhood as a whole represents an intermediate value between the extremes recorded for the individual points of view.

Besides, the urban elements identified as landmarks by the participants were investigated starting from the PoVs provided. Figure 4 shows the heatmap of the survey's results. Among the prominent landmarks identified by users, there are the Rectorate of the Politecnico, in front of piazza Leonardo daVinci, and the building that houses the Faculty of Architecture, immediately north of via Edoardo Bonardi. It is important to point out that the students who participated in the workshop belong to the Architecture and Urban Planning degree courses; it is therefore reasonable to argue that, in addition to the historical building mentioned above that symbolizes POLIMI, the facade of the School of Architecture and Society also has an important symbolic value for the students involved in the activity. It is interesting to underline that the presence of a landmark does not necessarily correspond to a positive emotional experience. PoV I and PoV 3 both include landmarks but are characterized by emotional experiences of opposite valence, negative for PoV I and positive for PoV 2 .

\section{Conclusions and future works}

The construction of a narrative of the experience of urban space through digital tools offers various opportunities. This narrative can be shared with citizens to connect different communities living in the same place and help creating a common representation. At the same time, Public Administrations can also benefit from this process; in fact, the outcomes of the analyses enable spatializing the prevailing emotions generated by the experience of places to inform urban policies and projects. The use of VR allows collaboration even remotely, overcoming the problems related to people gatherings imposed by the emergency regulations due to the COVID pandemic. The graphic rendering of the results favors and informs the discussion with citizens and stakeholders, facilitating the comparison between individual perceptions and collective vision. Although the case study was conducted with a limited number of participants and with a specific target compared to the ensemble of residents in the neighborhood, the method and process applied made it possible to inform the development of a mobile app (AR4CUP, commercially CitySense) to support the co-design processes. Other case studies are planned to be applied to the current urban state or urban projects. The set of case studies will allow validating the methodology in actual contexts of various kinds. 
Fig. 4. Heatmap of the landmarks evaluated through the pre-

determined and free PoVs.

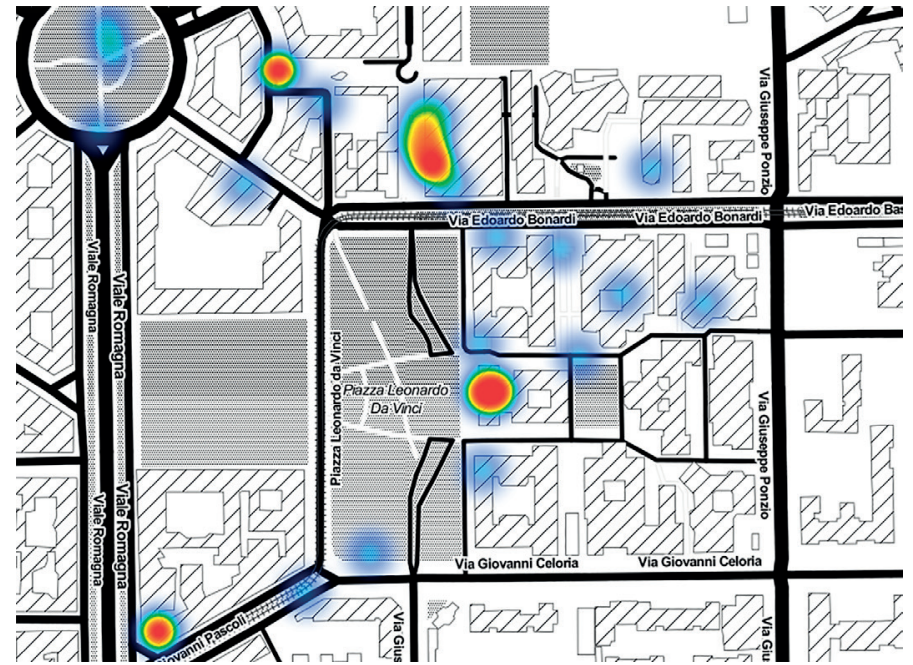

\section{Acknowledgments}

This project has received funding from the European Union EIT Digital research and innovation program Horizon 2020 AR4CUP | Augmented Reality for Collaborative Urban Planning (2019 and 2020). The responsibility for this publication lies solely with the author. The European Union is not responsible for any use that may be made of the information contained therein.

\section{Notes}

[I]That <https://citysense.fr/en/> (accessed 202I, April 20)

[2] Politecnico di Milano, Departement of Architecture and Urban Studies, Laboratorio di Simulazione Urbana, Fausto Curti.

[3] Università degli Studi di Milano, Departement of Cultural Heritage and Environment.

\section{References}

Al-Kodmany K. ( 1999). Using visualization techniques for enhancing public participation in planning and design: Process, implementation, and evaluation. In Landscape and Urban Planning, 45(1), pp. 37-45.

Al-Kodmany K. (2002).Visualization Tools and Methods in Community Planning: From Freehand Sketches to Virtual Reality. In Journal of Planning Literature, I7(2), pp. I89-2। I.

Birant D., Kut A. (2007). ST-DBSCAN: An algorithm for clustering spatial-temporal data. In Data \& Knowledge Engineering, 60(I), pp. 208-22I.

Boffi M., Rainisio N. (2017). To Be There, or not to Be. Designing Subjective Urban Experiences. In Piga B.E.A., Salerno R. Urban Design and Representation, pp. 37-53. Cham: Springer International Publishing.

Bosselmann P. (1998). Representation of Places: Reality and Realism in City Design. USA: University of California Press.

Bosselmann P. (2012). Urban Transformation: Understanding City Form and Design. USA: Island Press.

Brauer B., Ebermann C., Hildebrandt B., Remané G., Kolbe L.M. (20 I6). Green by App:The Contribution of Mobile Applications to Environmental Sustainability, pp. I-17. In PACIS 2016. Chiayi City, Taiwan: AISeL.

Desouza K. C., Bhagwatwar A. (20|4). Technology-Enabled Participatory Platforms for Civic Engagement: The Case of U.S Cities. In Journal of Urban Technology, 2 I (4), pp. 25-50.

Evans-Cowley J., Hollander J. (20 I0).The New Generation of Public Participation: Internet-based Participation Tools. In Planning Practice \& Research, 25(3), pp. 397-408

Kanhere S.S. (20I3). Participatory Sensing: Crowdsourcing Data from Mobile Smartphones in Urban Spaces. In Hota C., Srimani P.K. (Eds.). ICDCIT 2013 , International Conference on Distributed Computing and Internet Technology, pp. I9-26 Bhubaneswar, India: Springer.

Lundgren S. et al. (20I5). Designing Mobile Experiences for Collocated Interaction. In D. Cosley and A. Forte (Eds.). Proceedings of the 18th ACM Conference on Computer Supported Cooperative Work \& Social Computing, pp. 496-507. New York: ACM. <https://doi.org/|0.1 |45/2675 | 33.2675 I7|> (accessed 202I, May 23).

Münster S. et al. (2017). How to involve inhabitants in urban design planning by using digital tools? An overview on a state of the art, key challenges and promising approaches. In Procedia Computer Science, I I 2, pp. 239 |-2405.

Peng Z.R. (200 I). Internet GIS for Public Participation. In Environment and Planning B: Planning and Design, 28(6), pp. 889-905. 
Piga B., Morello E. (20 I5). Environmental Design Studies on Perception and Simulation: An Urban Design Approach. In International Journal of Sensory Environment, Architecture and Urban Space, n. I, pp. I-24.

Piga B.E.A. (2017). Experiential Simulation for Urban Design: From Design Thinking to Final Presentation. In B. E. A. Piga, R Salerno (Eds.). In Urban Design and Representation: A Multidisciplinary and Multisensory Approach, pp. 23-36. Cham: Springer International Publishing.

Piga B.E.A. (20।8). The Combined Use of Environmental and Experiential Simulations to Design and Evaluate Urban Transformations. In R. Cocci Grifoni, R. D'Onofrio, M. Sargolini (Eds.). Quality of Life in Urban Landscapes, pp. 357-364. Cham: The.

Piga B.E.A., Boffi M., Rainisio N., Stancato G. (2019). Augmented Reality for Co-Design:The Perspective of Real Estate Developers, Architectural Firms, And Public Administrations. In CTV 2019 Proceedings: XIII International Conference on Virtual City and Territory: "Challenges and Paradigms of the Contemporary City", pp. I - I 5. Barcelona: Centro de Política de Suelo y Valoraciones (CPSV) UPC.

Piga B.E.A., Cacciamatta S., Boffi M. (202I). Smart Co-Design for Urban Planning:Augmented and Virtual Reality Apps in Collaborative Processes. Springer International Publishing. <https://www.springer.com/gp/book/97830306784I8> accessed 2021, May 23).

Russell, J. A., \& Pratt, G. (1980). A description of the affective quality attributed to environments. In Journal of Personality and Social Psychology, 38(2), pp. 31 | -322.

Sanders E.B.N. (2002). From user-centered to participatory design approaches. In Frascara J. (Ed.). Design and the Social Sciences, vol. 20020425, pp. I-8. CRC Press. <https://doi.org/I 0.1201/978020330I302.ch I > (accessed 202 I, May 23).

Stancato G., Piga B. (2020). La simulazione parametrica come strumento per informare la rappresentazione | Parametric Simulation as a Tool to Inform Representation. In Arena A., Arena M., Brandolino R.G., Colistra D., Ginex G., Mediati D., Nucifora S., Raffa P. (a cura di). Connettere. Un disegno per annodare e tessere. Atti del $42^{\circ}$ Convegno Internazionale dei Docenti delle Discipline della Rappresentazione/Connecting. Drawing for weaving relationships. Proceedings of the 42th International Conference of Representation Disciplines Teachers, pp. 829-846. Milano: FrancoAngeli.

Stratigea A., Papadopoulou C.A., Panagiotopoulou M. (20I5). Tools and Technologies for Planning the Development of Smart Cities. In Journal of Urban Technology, 22(2), pp. 43-62.

\section{Authors}

Barbara Piga, Politecnico di Milano, barbara.piga@polimi.it

Gabriele Stancato, Politecnico di Milano, gabriele.stancato@polimi.it

Nicola Rainisio, Università degli Studi di Milano, nicola.rainisio@unimi.it

Marco Boffi, Università degli Studi di Milano, marco.boffi@unimi.it

Giulio Faccenda, Politecnico di Milano, giulio.faccenda@polimi.it

To cite this chapter. Piga Barbara, Stancato Gabriele, Rainisio Nicola, Boffi Marco, Faccenda Giulio (2021). Emotions and Places. An Investigation through Virtual Reality. In Arena A. Arena M. Mediati D. Raffa P (a cura di) Connettere. Un disegno per annodare e tessere. Linguagoi Distanze TecnoDistances Techno 